\title{
BBS Valedictory Editorial
}

BBS was an idea 25 years before its time - 55 years if you reckon it by the advent of its model, Current Anthropology, CA, founded by Sol Tax in 1957 (Harnad 1978, 1979). It is only now, in the online era, that the Open Peer Commentary feature will at last come into its own. I wish BBS every success in its 2nd half-century. I expect that BBS's Commentary feature, inspired by CA, and emulated by several other journals across the years, will become ever more widespread online. I never believed that only 12-15 target articles a year deserved this treatment, but limits of time and journal space and budget made it impossible to treat more. This will change now.

But what will not change is what must come first, for every target article accorded open peer commentary first undergoes a particularly rigorous form of classical peer review. The rigor was partly because we could only afford to accept so few, yet I've often wondered whether many of the papers we had to turn down across the years, some of which went on to appear in excellent journals, would not have generated BBS treatments that were as valuable for both the readers and the authors as the ones we did publish.

This does not mean a decline in my belief in peer review! There are at least 20,000 peer-reviewed journals, across disciplines and around the world, publishing at least 2,000,000 articles annually. No reader should ever have to face the raw, unrefereed drafts out of which those 2,000,000 articles grew - that is the job of the intrepid editor and those unsung heroes, the selfless referees. The filter of peer review protects the scarce and precious time of all researchers, in ensuring that what does appear can be trusted to have met established quality standards of the journal in which it appears. But after that, after the respective quality-standards have been met, that is certainly not the end of it. We know, of course, that many published articles are never cited, and probably many of those are never even read. And no doubt many do deserve that fate. But my concern is with those that do not: those stillborn brainchildren that would have needed some peer commentary to draw attention to their merits (and perhaps also their defects).

In the paper era, the turn-around time and the costs minimized the possibility of such formal (i.e., published) peer feedback, but the PostGutenberg era of Scholarly Skywriting seems almost made to measure for it. BBS already uses the online medium more efficiently, extensively and creatively than most journals. Let me close with the confident prediction that this is but the beginning.

To the 15,000+ BBS Associateship that grew out of the 100 original recipients of my 1977 "chain letter": I look forward to joining you as just another BBS Associate, free at last to comment now and again. Vale atque ave!

To the many BBS editorial staffers across the years (you know who you are, and the BBS archival mastheads bear lasting witness!), and especially to Ursula, Helaine, ChooiYeok, Nancy and Phin: my lifelong gratitude.

To my successor-editors - Barbara, Jeffrey and Paul, as well as to the members of the newly formed BBS inner editorial circle - it is gratifying to know that no one mortal now stands in that loco parentis that I had gotten so used to thinking of as mine alone! Corragio!

And to you, my own brainchild, BBS, let me bid a personal farewell: I have not orphaned you, I hope you know, though the weaning has caused us both some pain. I've just made way for your skyward voyage: Godspeed!

Stevan Harnad

Harnad, S. (1978) Editorial. Behavioral and Brain Sciences. http://www.ecs.soton.ac.uk/ harnad/Temp/Kata/bbs.editorial.html

Harnad, S. (1979) Creative disagreement. The Sciences 19: 18-20. http://www.ecs.soton.ac.uk/ harnad/Temp/Kata/creative.disagreement.html

Harnad, Stevan (1985) Rational disagreement in peer review. Science, Technology and Human Values, 10 p. 55-62. http://cogprints.soton.ac.uk/documents/ disk $0 / 00 / 00 / 21 / 28 /$

Harnad, S. (1990) Scholarly Skywriting and the Prepublication Continuum of Scientific Inquiry. Psychological Science 1: 342-343 http://cogprints.soton.ac.uk/documents/disk0/00/00/15/81/

Harnad, S. (1991) Post-Gutenberg Galaxy: The Fourth Revolution in the Means of Production of Knowledge. Public-Access Computer Systems Review 2(1): 39 $53 \mathrm{http} / / /$ cogprints.soton.ac.uk/documents/disk0/00/00/15/80/

Harnad, S. (1998/2000) The invisible hand of peer review. Nature [online] (5 Nov. 1998) http://cogprints.soton.ac.uk/documents/disk0/00/00/16/46/

Harnad, S. (2003) Back to the Oral Tradition Through Skywriting at the Speed of Thought. Interdisciplines. http://www.interdisciplines.org/ defispublicationweb/papers/ 6 